\title{
A FIGURAÇÃO DE UM TEMPO DE EXTREMOS: ERICO VERISSIMO E O SÉCULO XX
}

\section{THE FIGURATION OF A TIME OF EXTREMES}

\author{
Maria da Glória Bordini \\ Universidade Federal do Rio Grande do Sul, Programa de Pós-Graduação em \\ Letras, Porto Alegre, RS, Brasil
}

\begin{abstract}
Resumo: $\mathrm{O}$ presente artigo apresenta uma visão panorâmica da produção ficcional de Erico Verissimo, pensando-a na relação com eventos catastróficos do século XX. Tratou-se do período em que o desacordo dos artistas no tocante à sociedade burguesa e suas açóes levou a um isolamento das artes. Baseado no fato de que Verissimo adotou a transparência da estética realista, para o desagrado da crítica brasileira dominante, que valorizava experimentalismos de vanguarda, o artigo tenta esclarecer como se comporta a obra em questáo diante de temas como ditaduras, guerras, desigualdade, e ante a responsabilidade do escritor em denunciar tempos sombrios.
\end{abstract}

Palavras-chave: romance histórico; realismo; ficçẫo e sociedade.

Abstract: This article is a panoramic view of Erico Verissimo's novelistics, in relation to the several catastrophic events of the Twentieth Century. The modern artists' disgust with the bourgeois society and its deeds led to the isolation of the arts in themselves. He adopted the transparency of the realist aesthetics as an aim, to the dislike of the mainstream Brazilian criticism, that valued avant-garde experimentalisms. This article tries to clarify how it behaves the Erico Verissimo's novelistic in face of issues such as dictatorships, wars, inequality and the responsability of the writer in denouncing dark times.

Keywords: historical novel; realism; fiction and society.

O século XX, no entendimento de Eric Hobsbawm (1995, p. 1516), implica "uma Era de Catástrofe, que se estendeu de 1914 até depois da Segunda Guerra Mundial", seguida de mudanças extraordinárias na economia e nas sociedades, durante uns trinta anos, e assolada uma "nova era de decomposição, incerteza e crise", dos anos 70 em diante. É esse "breve século", no dizer do historiador, que o filósofo Isaiah Berlin lembra "apenas como o século mais terrível da história” (HOBSBAWM, 1995, p. 11).

O paradoxo de progressos e regressóes que marcou o século passado também repercute sobre a arte. Desde os tempos das vanguardas europeias, no início dos Novecentos, a desconfiança quanto à pureza de intençốes nas práticas sociais burguesas levou a arte e a literatura a encastelarem-se. A atividade artística em geral tornou-se uma esfera separada da práxis comum, 
distante do público, pois, em sua luta por resistir à alienação, primava pela subversão dos valores estabelecidos, fossem quais fossem, linguísticos, estéticos, sociais, econômicos. No Brasil, essa trajetória não foi diversa.

Consciente que o abismo entre arte e público poderia ser a morte da literatura num país de poucos leitores, Erico Verissimo empenhouse por torná-la outra vez significativa para o homem comum, a quem os tormentos da lucidez soam irrelevantes diante da dureza do cotidiano. A preocupação em dialogar com o leitor, numa troca simétrica de visóes da realidade e de prospecçóes do que esta poderia se tornar, valeu-lhe a etiqueta de autor concessivo, escritor menor, mas não o demoveu, ao longo da vida, de continuar o diálogo de modo a ser compreendido o menos discriminadamente possível.

É assim que seu romance adere à memória popular: nele, a vida histórica se ficcionaliza em arte, permitindo, na urdidura das açóes e personagens, o reconhecimento dos destinos pelo leitor como coisa sua. Uma e outra, porém, sofrem o influxo dos tempos, diferenciando-se conforme estes se alteram, de um extremo a outro, como sugere Hobsbawm sobre o século passado. O que mantém a unidade de interesse de sua obra é a coerência ética de Verissimo, que, respondendo antecipadamente à conclamaçáo de Edward Said aos intelectuais (2005), assegura a seus leitores que não serão traídos, não em tempos de crise, nem em tempos de bonança.

\section{A doce-amarga experiência da modernidade}

Os primeiros romances de Erico Verissimo, Clarissa (1933), Caminhos Cruzados (1935), Música ao Longe (1935), Um Lugar ao Sol (1936), Olhai os Lírios do Campo (1938), Saga (1940), O Resto é Silêncio (1943) e Noite (1954), náo nascem inocentes. Centrados na vida cotidiana do interior e da capital do Rio Grande do Sul, contam histórias de decadência e de autotransformação. Sáo tributários do Modernismo de 1922, com sua recusa ao academicismo e ânsia de atualização formal. Erico lia os dois Andrades com certa perplexidade, trazendo, como tantos outros escritores sulinos, um repertório de leituras que privilegiava o realismo de um Eça de Queirós ao lado de um racionalismo à Voltaire e de um lirismo campestre à Francis Jammes. Com esse background de leituras, é explicável que tanto Clarissa (VERISSIMO, 1933) como Música ao Longe (VERISSIMO, 1935) esboçassem o retrato delicado de uma adolescente a descobrir as agruras da vida. Já Caminhos Cruzados (VERISSIMO, 1935) responde ao impulso engajado do Romance de Trinta, sob o influxo 
do neorrealismo norte-americano. Erico refina sua técnica, introduzindo as sequências contrapontísticas, aprendidas em Manhattan Transfer, de Dos Passos, e nos Faux-Monnayeurs, de Gide, ambos de 1925, e em Point Counterpoint, de Huxley, traduzido por ele em 1933.

A redenção pela arte, claramente proposta aos jovens de Um Lugar ao Sol (VERISSIMO, 1936), responde à fase de consolidaçáo do segundo modernismo. Ou a literatura apresentava o retrato desolador da miséria brasileira, sem saídas para quem está na base da pirâmide social, como nos luminares da Geração de 30, ou o impasse poderia ser resolvido pelo refúgio na arte, como advogavam os vanguardistas europeus. Essa foi a opçáo de Erico, fazendo do desempregado pintor Vasco Bruno a personagem-chave na figuração de uma Porto Alegre dominada pelo negócio e pelo capital.

A Segunda Guerra progredia e, enveredando por uma linha de defesa do humanismo via arte, Saga (VERISSIMO, 1940), romance que segue o esperançoso Olhai os lírios do campo (VERISSIMO, 1938), história da redenção do médico Eugênio, inaugura um posicionamento transnacional na obra de Verissimo. Antibelicista por convicção, que no ano de 1935 assinara um manifesto antifascista, em protesto contra a invasão da Abissínia por Mussolini (Solo de Clarineta), Erico alista o Gato do Mato, do ciclo de Clarissa, como voluntário na Brigada Internacional durante a Guerra Civil Espanhola, com base no diário de um combatente gaúcho que dela participara.

Sua autocrítica o demove do experimento com a ficção autobiográfica, possivelmente porque reconhece em seu estilo narrativo a tendência à fragmentação, ao insight de superfície, em pedaços, enquanto a narração subjetiva exige um mergulho interior que ele temia não conseguir exercer em sua arte compositiva. Assim é que o próximo romance que publica, $\mathbf{O}$ Resto é Silêncio (VERISSIMO, 1943), retorna à técnica de contraponto, mas associada a focos narrativos mais densos: trata-se do suicídio de Joana Karewska, cabendo uma sequência narrativa a cada testemunha, interrompida por várias intromissóes em contraponto. Diante da progressiva indiferença das testemunhas ao acontecido, apenas o escritor Tônio Santiago não esquece Joana e busca elucidar o caso.

De novo, é à arte que Erico empresta valor humanístico: no trecho final, após haver desvendado em parte o mistério da morte de Joana, Santiago ouve a Quinta Sinfonia de Beethoven no Theatro São Pedro. Ante a plateia de variada composição étnica, ele imagina a filiação ancestral desse público, numa linha de tempo que remonta às missôes jesuíticas nas terras guaranis. É nessa rememoraçáo das origens, nesse rearranjo ficcional da 
História que Santiago encontra nova esperança civilizatória para os atuais tempos da Segunda Guerra, que o atormentam. Na evocação do passado de lutas e extremas dificuldades que permitiu aquelas presenças numa audição culta, está em semente da ideia de $\mathbf{O}$ Tempo e o Vento, sua obra máxima, que Erico publicaria entre os anos de 1949 a 1962.

Durante a elaboração da trilogia, desenvolvendo o que ele denomina de arranjos sinfônicos dos três volumes ${ }^{1}$, o momento de sombra volta a emergir. Ele escreve $\mathbf{O}$ Continente e $\mathbf{O}$ Retrato, remontando à formaçáo da Província de São Pedro, em 1745, nas missóes guaraníticas, para alcançar o atual Rio Grande do Sul de 1945, à queda de Getúlio Vargas. Vai das origens míticas à demoliçáo do mito (ZILBERMAN, 1986, p. 63-90), mas nesse processo estaca. O fato é que Erico, desgostoso com os rumos autoritários do segundo governo getulista, aceitara o cargo de diretor do Departamento de Assuntos Culturais da União Pan-Americana (UPA), em Washington, de 1953 a 1956 - e a escrita do terceiro volume ficou adiada até sua volta ao Brasil.

No ano do suicídio de Getúlio Vargas, 1954, Erico, numa de suas rápidas voltas no Rio Grande do Sul, escreve de chofre a novela Noite (VERISSIMO, 1954), cujo título parece sugerir simbolicamente a situação de bloqueio criativo em que a trilogia se encontrava. História de um indivíduo amnésico que atravessa a noite de uma grande cidade em busca de sua identidade, acompanhado por um gigolô mefistofélico e um desenhista corcunda e sádico, o romance do Desconhecido afasta-se da predominância da claridade que caracterizara todo o romance urbano do autor. Insinua-se no texto uma simpatia pelo lado obscuro da personagem, que corresponde ao fascínio exercido mais tarde pelo corrupto Dr. Rodrigo sobre seu filho Floriano, o narrador de O Arquipélago (VERISSIMO, 1961).

Importa, porém, é que Noite (VERISSIMO, 1954) encerra a série de romances explicitamente urbanos do escritor. O retorno de Erico ao país, em 1956 - quando assume definitivamente a profissão de escritor, renunciando a seu papel de conselheiro editorial da Editora Globo e de agente cultural do Brasil na Organização dos Estados Americanos - não só proporciona a conclusão do terceiro volume da trilogia, em 1962, mas uma virada importante na produção romanesca do autor. Em $\mathbf{O}$ Arquipélago (VERISSIMO, 1961) essa mudança já está prefigurada, nas "Reuniôes de família”, quando o assunto de discussão no Sobrado do Dr. Rodrigo, com

\footnotetext{
${ }^{1}$ No rascunho de uma entrevista a respeito de $\mathbf{O}$ arquipélago (Acervo Literário de Erico Verissimo - ALEV 01i0047- sd, p. iii), Erico menciona uma "longa sinfonia dividida nos clássicos movimentos e possivelmente com grandes massas corais".
} 
seus filhos e amigos, é constantemente a política local e nacional e o jogo das ideologias.

\section{No limiar da pós-modernidade}

Erico, ao conhecer de perto os meandros da diplomacia de Washington, parece ter revisado sua simpatia pela política externa dos Estados Unidos, manifestada - apesar de forte dose de ironia - em seus livros de viagens Gato Preto em Campo de Neve (1941) e A Volta do Gato Preto (1946). Em suas estadas anteriores nos EUA, no período da Segunda Guerra, o que ele vira fora a mobilizaçáo dos norte-americanos na defesa da liberdade e os benefícios que a civilização da alta tecnologia, da livre imprensa e da justiça para todos trouxera àquela nação sob Roosevelt.

Anos depois, quando dirigia o Departamento de Assuntos Culturais da UPA (OEA), visitou diversos países centro e sul-americanos e percebeu as intençóes imperialistas dos Estados Unidos, que à época estavam empenhados no combate à sovietização da América do Sul, no auge da Guerra Fria.

$\mathrm{O}$ escritor, trazendo à baila a discussão ideológica em $\mathbf{O}$ Arquipélago (VERISSIMO, 1961) e opondo dialeticamente posiçóes inconciliáveis como as do comunista Eduardo e do terratenente Jango, superadas pelas de Floriano, outra vez o porta-voz da arte e do humanismo, prepara o caminho para outro tipo de romance, o de decidido fundo político. O Senhor Embaixador (1965), O Prisioneiro (1967) e Incidente em Antares (1971) mantêm-se fiéis às técnicas narrativas praticadas por Erico nos romances urbanos e na trilogia histórica, com episódios entrecruzados e encaixados uns nos outros, mas o espírito dos relatos é diverso. Questiona-se eticamente o direito de intervenção externa nos assuntos internos das naçóes, nos dois primeiros, e a estrutura moral de uma sociedade que viola os direitos mais fundamentais de seus cidadáos, os de viver e de morrer com dignidade.

O Senhor Embaixador (VERISSIMO, 1965) lembra Saga (VERISSIMO, 1940), com seus supostos defeitos corrigidos. A obra dividese em duas partes, uma na embaixada de Sacramento em Washington, movimentando o carrossel das intrigas e manobras palacianas para consolidar a ditadura no fictício país centro-americano, e a outra na ilha em que o povo toma a si a revolução, conduzido à guerrilha por líderes imbuídos dos ideais leninistas. Entre esses dois territórios simbólicos, vagueia a indecisa figura de Pablo Ortega, pintor e poeta, adido cultural do embaixador Gabriel 
Heliodoro Alvarado, constrangido por ter de apoiar o representante da ditadura de seu país, mas admirando sua bravura e lealdade ao regime.

O romance estuda com perspicácia personalidades das esferas políticas dos anos 60, ao abrigo de um país cujo nome evoca sub-repticiamente à Colônia do Sacramento, regiáo diretamente atingida pela Operação Condor no extremo-sul da América Latina. O Senhor Embaixador (VERISSIMO, 1965) saiu um ano depois do golpe militar de 1964 e a conclusão a que Pablo chega, ante seus dilemas, é favorável, embora difícil de engolir pela própria personagem, à revolução armada. Nessa mesma época, gestavam-se os movimentos guerrilheiros no Brasil, que alcançariam seu ápice no início dos anos 70. Tratar de um tema desses, num país dividido entre extremistas de direita e esquerda, pesando os prós e os contras de cada lado, era um ato de coragem política, que raros escritores da época emularam.

Outro gesto inusitado de Erico Verissimo foi abandonar a discussão da nacionalidade, da identidade brasileira, que vinha repetindo-se desde o romantismo alencariano, para aventurar-se por terras estrangeiras, examinando suas opçóes políticas e o destino de suas utopias. Seu interesse se volta outra vez para a guerra, desta vez a dos EUA contra o Vietná do Norte, em O Prisioneiro, de 1967. Erico assume o risco de tratar de dois conflitos internacionais, na sequência de uma produçáo literária que o consagrara no romance histórico, impelido pela urgência de comprometerse eticamente com outro modelo de humanidade, o qual náo implicasse a matança por ideias e interesses.

O Prisioneiro (VERISSIMO, 1967) toma a forma de uma parábola antibelicista, em que um Tenente norte-americano negro deve extrair de um guerrilheiro vietnamita uma confissão de importância vital para a segurança da cidade ocupada (cujo modelo foi Hue), ao preço de sua própria integridade moral. A abominação da tortura, praticada por razóes de autodefesa do Estado, de mistura com a autojustificação de estar guerreando um inimigo que não hesita em adotar técnicas terroristas contra inocentes civis, é o ponto central da história de $\mathbf{O}$ Prisioneiro, permitindo a Erico o exame, outra vez, das legitimaçóes ideológicas para atos desumanos.

Talvez para atender à grita de que se desviara da denúncia da crise institucional de seu próprio país, talvez porque a incursão pelo estrangeiro lhe tivesse provado a possibilidade da metaficçáo historiográfica de que fala Linda Hutcheon (1980), sob a forma de romance contra-ideológico, Erico prossegue sua produção romanesca com um texto-estuário, Incidente em Antares (VERISSIMO, 1971). 
Neste, confluem a sátira dos romances urbanos, a revisão da História pela ótica de dominadores e dominados praticada na trilogia, e a acuidade da visão política dos dois romances anteriores. Dividida em duas partes, "Antares" e "O Incidente", a história focaliza uma cidade interiorana, eco remoto de Jacarecanga de Música ao Longe (VERISSIMO, 1935), governada por uma súcia de políticos e juristas corruptos, mancomunados com grandes indústrias estrangeiras fixadas na região. Nada seria mais semelhante à situação do país à época da ditadura militar.

O livro, inovadoramente, pratica uma intertextualidade intraliterária, pois, para expor as razóes históricas desse comportamento dos próceres de Antares, relata, como ocorre na trilogia, a formaçáo dessa sociedade autoritária. O que havia de substrato mítico na obra intratextualizada, $\mathbf{O}$ Tempo e o Vento (1949-1962), nesse romance é inteiramente ignorado. Os começos são brutais, e seus desenvolvimentos também. A história de duas famílias rivais disputando o poder local persiste, mas sob tom paródico. Quando irrompe o absurdo, com o despertar dos mortos em seus caixóes, ocasionado pela greve geral que impede os coveiros de trabalharem, as personagens-tipo da trilogia são condensadas e reescritas. No advogado, na ricaça, no operário, no anarquista, no bêbado, na prostituta e no músico ressoam os bacharéis, as senhoras do Sobrado, especialmente Bibiana, o pintor e anarquista D. Pepe, os populares, amigos do Dr. Rodrigo, as chinas, enfim, os funcionários públicos aliados do governo, as mulheres influentes e a raia miúda, que se erguem para pôr a nu as torpezas do poder.

Com esse procedimento intertextual e autoparódico, Erico consegue, ao mesmo tempo, criar uma nova parábola contra a ditadura militar e revisar sua própria revisão da História. Contudo, não abre mão da utopia humanista, representada pela fuga da mulher e do filho de João Paz, justamente a família operária oprimida que teria possibilidades, num futuro não entrevisto, de modificar o status quo. A técnica do romance também se desdobra num leque de alternativas, incluindo o diário de Martim Francisco, as reportagens de Lucas Lesma, os extratos de narrativas de viajantes, os diálogos das personagens, retomando a polifonia de vozes que despontava em Clarissa (VERISSIMO, 1933), mas desta vez impregnada de interesses menos pessoais e mais políticos.

Depois de O Arquipélago (1961), Erico põe em ação uma arte romanesca diversa da que empreendera até então. Não há mais figuraschave nem perspectivas privilegiadas. Incidente em Antares (VERISSIMO, 1971) é o ponto culminante desse novo empreendimento estético: nele não se encontram soluçóes definitivas, tudo se relativiza e até mesmo o 
sobrenatural - recurso infalível do realismo mágico latino-americano para casos extremos de opressáo como o de Antares - falha em decretar a volta à normalidade, pois a cidade não muda após o maravilhoso do incidente que nela ocorre. Por outro lado, Erico não deixa de manifestar seu próprio esquema de valores, o que faz por algum porta-voz, como em toda sua obra (nesse caso, por Martim Francisco Terra). A diferença é que esse credo já não impregna todo o romance, proporcionando maior latitude para as personagens entrarem em dissenso.

\section{Presente e passado em tempos extremos}

Pensando o último século, o historiador da literatura Miklós Szabolcsi (107-231) nele observa, tal como Hobsbawm, nos anos 1920, uma fase antibelicista, após a Primeira Guerra Mundial, entusiasmada com o advento da revoluçáo comunista, contrabalançada por uma virada à direita, em virtude das dificuldades da economia do pós-guerra; nos anos 1930, salienta o crescimento de um sentimento antifascista, uma última esperança de "união das forças progressistas", desmantelada pelos desmandos do stalinismo; nos anos 1940, um clima de catastrofismo durante a Segunda Guerra Mundial; nos anos 1950, uma nova fase de esperança com as conquistas tecnológicas da física, da eletrônica e da biologia; nos anos 1960 e décadas posteriores, um desencanto agora descrente de que a ciência ou a arte pudessem alterar as condiçôes de vida, por mais que ambas tivessem ultrapassado os limites do pensável.

Há, entre esses tempos, uma continuidade e uma ruptura que embaralham qualquer divisão expressa. Entre os autores modernos, o que fazia um Joyce, experimentalista, náo era o que se encontrava em um Thomas Mann, o realista. É difícil situar os escritores hoje tidos como pós-modernos num campo diverso desses modelos, quando se pensa num John Fowles ou num Thomas Pynchon, em Michel Houellebecq ou Sérgio Santana, que poderiam ser filiados às vanguardas do romance, ou em um Umberto Eco, Phillip Roth, Ian McEwan, Jonathan Littell ou Rubem Fonseca, que se alinhariam aos novo-realistas. Nos dois campos, densamente povoados, do romance do Século XX, está inserida a produção de Erico Verissimo, que recolhe tanto a fragmentaçáo, as sequências entrecruzadas e a busca identitária da primeira metade do século, quanto a lição autodesconstrutiva e paródica da segunda metade, mantendo-se constante na revisitação da História pela perspectiva de opressores e oprimidos, e adotando pontos de vista pós-coloniais avant la lettre, sem descrer nas possibilidades 
emancipatórias da arte.

Seu romance responde aos apelos da História, servindo-lhe de memento e corretivo em tempos particularmente sombrios. Do desinteresse pelo tempo, que está no âmago da vida urbana, a qual funciona mais espacial do que temporalmente, e que se manifesta na estética moderna pela fragmentação e montagem, Erico chega ao hibridismo do presente com o passado, típico do pensamento atual, e cultiva o romance histórico, não apenas voltado para a história pregressa, mas para a história do seu presente. E esse era um presente em que o Brasil soçobrava num regime de força, que se legitimava por uma luta aparentemente anticomunista, inspirada pelos rescaldos da Guerra Fria, mas em que se desenhava, em todo o mundo, um novo imperialismo e uma nova dependência, os da sociedade de consumo, do capital volátil, da globalização uniformizadora, e de modos ardilosamente sutis de repressão à dissidência e à diferença.

\section{Referências}

HOBSBAWM, Eric. Era dos extremos: o breve século XX. 1914-1991. 2. ed. São Paulo: Companhia das Letras, 1995.

HUTCHEON, Linda. Narcissistic narrative - The metafictional paradox. Nova York: Methuen, 1980.

SAID, Edward W. Representaçóes do intelectual. São Paulo: Companhia das Letras, 2005.

SZABOLCSI, Miklós. Literatura universal do século XX - Principais correntes. Brasília: Ed. UnB, 1990,

VERISSIMO, Erico. Solo de clarineta. v.1. São Paulo: Companhia das Letras, 2005.

ZILBERMAN, Regina. O tempo e o vento, história, mito, literatura. Letras de Hoje, Porto Alegre: PUCRS, n. 65, p.63-90, set. 1986. 